\title{
0859 CHILD RESTRAINTS A CROSS-SECTIONAL STUDY ON KNOWLEDGE, ATTITUDE AND PRACTICE OF TRAFFIC POLICE IN UNITED ARAB EMIRATES
}

M Grivna*, H Al-Shamsi, A Al-Hammadi, M Al-Obthani, M Al-Ali, A Al-Senani, M El-Sadig, R Bernsen, P Barss Correspondence: Faculty of Medicine \& Health Sciences, United Arab Emirates University, PO Box 17666, FMHS, UAEU AIAin, United Arab Emirates

\subsection{6/ip.2010.029215.859}

Introduction Traffic mortality in the United Arab Emirates (UAE) is high; 2000-2006 incidence was reported as 10.1 per 100000 person years for 0 - to 4-year-olds and 7.8 for 5 - to 14 -year-olds. A 2004 study found only 4\% of frontseated children and $1 \%$ in the rear restrained. Current legislation does not mandate child restraints (CRs); even for adults enforcement is limited. Since traffic police should be capable of supporting and enforcing regulations protecting children, their knowledge and attitudes toward CRs were assessed.

Methods A January to February 2008 cross-sectional survey in $\mathrm{Al} A$ in city included visiting each police station during shift changeover using self-administered questionnaires on sociodemographic characteristics, knowledge, perceptions and attitudes about CR.

Results The final sample included 260 traffic police (response $70 \%$ ), 56\% UAE citizens and $62 \%$ aged 25-34 years. For children $<12$-years-old, $94 \%$ felt rear seating was safest, although $3 \%$ chose the drivers lap. Misconceptions were greater respecting age-appropriate CRs, with $50 \%$ choosing booster seats as safest for infants, 48\% rear-facing seats for 1 - to 4 -year-olds, and 50\% rear-facing seats for 4 - to 8 -yearolds. CRs were felt necessary for front occupants among $86 \%$ and rear $87 \%$. Traditional views on causality of crashes were prevalent; $93 \%$ cited destiny as a factor, $17 \%$ evil eye and $15 \%$ jinns.

Conclusion Despite generally positive attitudes towards CRs, knowledge on age-appropriate types was limited and traditional views on causality prevalent. Education of police should include preventability of child injury and ageappropriate CRs. 